\title{
The Effect of Systematic Approach to Tracheostomy Care in Patients Transferred from the Surgical Intensive Care Unit to General Ward
}

\author{
Yooun-joong Jung ${ }^{1}$, Younghwan Kim², Kyuhyouck Kyoung ${ }^{3}$, Minae Keum ${ }^{3}$, Taehyun Kim ${ }^{2 * *}$ Dae seong Ma ${ }^{4}$, \\ Suk-Kyung Hong ${ }^{5}$ \\ ${ }^{1}$ Department of Nursing, Asan Medical Center, Seoul,; Department of Surgery, National Medical Center, Seoul, ${ }^{3}$ Department of Surgery, Ulsan University Hos- \\ pital, Ulsan; ${ }^{4}$ Department of Trauma Surgery, Gil Medical Center, Gachon University College of Medicine, Incheon; ${ }^{5}$ Division of Acute Care Surgery, Depart- \\ ment of Surgery, Asan Medical Center, University of Ulsan College of Medicine, Seoul, Korea
}

2018 November 33(4):252-259 / https://doi.org/10.4266/acc.2018.00248

\section{Corrigendum}

${ }^{*}$ Current affiliation: Division of Acute Care Surgery, Department of Surgery, Asan Medical Center,

We found an error in this article. The author's ORCID should be corrected as following: University of Ulsan College of Medicine, Seoul, Korea

From Younghwan Kim https://orcid.org/0000-0001-7895-0362

to Younghwan Kim https://orcid.org/0000-0003-3836-8743

We apologize for any inconvenience that may have caused.

Copyright () 2019 The Korean Society of Critical Care Medicine

This is an Open Access article distributed under the terms of Creative Attributions Non-Commercial License (http:// creativecommons.org/li-censes/by-nc/4.0/) which permits unrestricted noncommercial use, distribution, and reproduction in any medium, provided the original work is properly cited. 